\title{
Life after Connectivity: the Impact of the Community Mesh Network in Mahavilachchiya, Sri Lanka's E-village
}

\author{
Alisha Bhagat \\ Information and Communication Technology Agency, Sri Lanka \\ <alisha.bhagat@gmail.com>
}

\begin{abstract}
This paper examines the impact of a community wireless mesh network established in the village of Mahavilachchiya, Sri Lanka. The "e-village" in Mahavilachchiya, created through a partnership between government agencies and a local NGO, features Sri Lanka's first wireless mesh network and has been operational since October, 2006. This paper incorporates data collected from the government run ICT agency and partner organizations, as well as observations of daily Internet use in Mahavilachchiya. Additionally, a survey on Internet use was administered to 35 students in Mahavilachchiya. The current reach of ICT in the village is examined and recommendations are made for the implementation of future e-villages.
\end{abstract}

\section{Introduction}

The Information and Communication Technology Agency (ICTA) of Sri Lanka has created a pilot e-village in the rural village of Mahavilachchiya. The e-village, located in the NorthCentral Province, boasts Sri Lanka's first outdoor wireless mesh network. Since October 3rd, 2006, this network has brought high speed Internet connectivity to two schools and 28 homes.

The purpose of this paper is to analyze the after-effects of the wireless mesh network on the village of Mahavilachchiya. Is ICT accelerating socio-economic development as the project intended? This paper examines the ways in which ICT is being used in Mahavilachchiya and presents ways in which it can be used more effectively.

The e-village project has been included in the 2007 Sri Lankan government budget as well as included in the ten-year Mahinda Chintanaya created by the president of Sri Lanka, Mr. Mahinda Rajapaksha. ${ }^{1}$ The government of Sri Lanka is committed to replicating the e-village across the country. This paper studies the pilot e-village of Mahavilachchiya in order to create guidelines for replicating the e-village project.

This paper is organized into three parts. The first part describes the development and implementation of a mesh network in Mahavilachchiya. The second part uses survey data to examine the current uses of the Internet in Mahavilachchiya and the ways ICT is being utilized in the village. In the third section, the Mahavilachchiya e-village is critically examined and recommendations are made in order to make the e-village more effective.

\section{Part 1: Background, Planning, and Goals}

\footnotetext{
${ }^{1}$ Mathes, Rohan, "President Stresses Integrated Village Development" ( Daily News, 1/8/07, Sri Lanka), http://www.dailynews.lk/2007/01/08/
} 
The Information and Communication Technology Agency (ICTA) of Sri Lanka is a government agency under the President's office. ICTA focuses on 5 project areas, including e-Society under which the e-village project falls. ${ }^{2}$ The e-Society project area operates with the goal of "innovatively using ICT to meet the social and economic needs of the most vulnerable communities". The e-village initiative led by ICTA attempts to take the power of ICT to rural communities in Sri Lanka. The project also hopes to integrate these technologies into the lives of citizens so that they are used for economic, educational, and social development. According to the ICTA website "The primary objective of the project is to demonstrate the effective contribution of an IT infrastructure in accelerated socio-economic development. (In order) To provide increased opportunities for growth and a better quality of life for citizens in rural communities, particularly the youth, by using ICT as a tool and enabler for development."

The work of ICTA is not to question if Sri Lanka should have Internet connectivity, but rather to work on how Sri Lanka can join the ICT revolution as quickly and as cost-effectively as possible. ICT must be implemented in a way that has the deepest impact on people's lives. Sri Lankans need connectivity, especially rural Sri Lankans, for whom connectivity can improve job and business opportunities as well as improving the overall quality of life.

The physical and economic circumstances of Sri Lankan villages provide unique challenges to connectivity. Firstly, the ICT literacy of the country remains very low at roughly $10 \%$, according to a survey conducted by the Department of Census and Statistics in 2004 ${ }^{5}$. This is surprising considering that the general literacy of the country is one of the highest in South Asia. The lack of ICT literacy results in rural users staying away from computers and Internet applications. Secondly, high capital and operating costs place computers and connectivity out of the reach of many people. Lack of constant electricity and difficult terrain add to the barriers of connectivity in rural areas.

The lack of English education in rural areas creates an additional obstacle to ICT literacy as the majority of computers and computer programs are created with an English-fluent user in mind. Villagers are rarely exposed to the English language and even if taught basic computer commands, cannot relate to content on the Internet. There is very little existing Sinhala ${ }^{6}$ content on the Internet and the lack of content discourages users in villages from taking an interest in the Internet and using it to its fullest.

In the case of Mahavilachchiya, the introduction of ICT into the village was a local initiative. A local English teacher, Mr. Wanni, educated himself on a second-hand computer and gained a degree of computer literacy. In 1998 he created a NGO called the Horizon Lanka Foundation. Horizon Lanka was created for the purpose of educating village youth in ICT and English. Seeing the inadequacies of the local school system in providing students with marketable skills, Mr. Wanni used Horizon Lanka as a way of training students for jobs and connecting them with the outside world.

Over the years more computers were added and more children began to participate in the lessons. Around 400 students became ICT literate through Horizon Lanka. A computer center

2 The other project areas include Re-engineering Government, Information Infrastructure, ICT and Private Sector Investment, ICT Human Resources Development, and ICT Policy, Leadership, and Institutional Development

$3 \quad$ ICTA website, www.icta.lk

$4 \quad$ ibid

5 Satharasinghe, Dr.Amara, "Computer Literacy of Sri Lanka” ( Department of Census and Statistics, 2004) http://www.statistics.gov.lk/cls2004/index.htm

6 Sinhala is one of the two national languages of Sri Lanka. The other is Tamil. 
was set up in the village. Using a website, the students solicit donations of equipment and help local families to purchase computers. Thanks to these programs, over 30 students have computers in their homes. The villagers found ways to better integrate computers into their lives. The children started to use more advanced programs and learned web design and graphic design. The Horizon Lanka Foundation designed its own website and uses it to promote Horizon Lanka and the work of the students.

What makes Horizon Lanka so remarkable is that the organization operates in a little known village - Mahavilachchiya -- $40 \mathrm{~km}$ from the nearest town Anuradhapura, and surrounded on three sides by the Vilpattu jungle. The population of Mahavilachchiya is 22,000 with 6,100 households. ${ }^{7}$ Most of the villagers are either farmers or laborers with a monthly income of about Rs. 5,000 - 10,000 (US\$ 50 - 100). Though there is electricity, it was only recently, in December 2006, that the village was connected to the telephone network.

Initially the students traveled to Anuradhapura, over $40 \mathrm{~km}$ away, in order to use the Internet. The high cost of travel to Anuradhapura as well as the high charges in Internet cafes greatly limited Internet use amongst the village students. In 2004 a tower was erected at the Horizon Lanka facility to get Internet signals. Through the work of the Horizon Lanka foundation, Internet was available in Mahavilachchiya at the Horizon center.

The tower at the Horizon Lanka site brought Internet to Mahavilachchiya but many students found it difficult to come to the center daily. Family obligations and long travel distances in Mahavilachchiya made it difficult for students to commute. By 2005 many Horizon Lanka students already had computers in their homes and as a result students and their families preferred to use the computer from home.

The Horizon Lanka foundation had already laid the groundwork for developing Mahavilachchiya as the first e-village site. Because of Wanni's years of teaching, the local youth are both fluent in English and computer literate. Furthermore, the Horizon Lanka foundation has worked to provide local students with computers and set up a computer center.The unique situation of Mahavilachchiya as a village in which there was already high ICT literacy and computer penetration, made it a perfect choice for the implementation of a wireless network which would reach students in their homes.

The Mahavilachchiya e-village was created through a partnership between ICTA, Horizon Lanka, Enterprise Technology (Pvt) Ltd (ETPL), and the Asia Pacific Development Information Program (APDIP) of the United Nations Development Program. ETPL constructed the mesh network, APDIP provided the funding, and ICTA coordinated all four participating organizations.

\section{Deciding on the Mesh}

Mesh networking is one of the most robust networks for rural connectivity. The network is resilient and self-healing and can recover if one or more nodes go down. Once the network is implemented, there is no cost for additional clients within the network, making it ideal for a low-income rural setting. The wireless mesh network in Mahavilachchiya is the first rural mesh network in Sri Lanka and was implemented by ETPL, who first introduced this technology to Sri Lanka. ${ }^{8}$

\footnotetext{
7 District Secretariat, Mahavilachchiya, Anuradhapura, statistics compiled for 2006.

$8 \quad$ Enterprise Technology (Pvt) Limited website, http://www.enterprisetl.com
} 
Numerous setbacks caused by large increases in the cost of certain items resulted in the budget doubling from the initial estimate. Additional costs resulted from the changes in recipient location and many unforeseen delays occurred in the process of obtaining the frequency license from the Telecommunications Regulatory Commission (TRC). Specifically, there were cost increases in the towers for the mesh box enclosures, the lightening and surge protectors, the antenna mounting, the TRC license fees, and the cost of tower construction. ${ }^{9}$ In future e-village projects these cost increases could be avoided through better planning.

\section{Goals of the Project}

The project objectives according to the final mesh network project report ${ }^{10}$ were as follows;

- promoting the use of computers in school and training

- facilitating the search for economic opportunities

- community chat

- dissemination of health and educationally important information, and

- spreading information on how to face current environmental conditions

Fulfillment of Goals

Promoting the use of computers in school and training

The accessibility of the Internet has encouraged local students to use the Internet as an educational tool. Many students use the Internet to search for information for research papers. Internet usage has fostered English language skills and has improved written and spoken English considerably. After the introduction of computers into homes, 6 students received an "A" grade for their O-level examinations. This was seen as a major accomplishment in the village.

Potential use: e-learning in local languages such as distance education courses offered by universities. Also, students could apply for scholarships and educational programs from home.

Facilitating the search for economic opportunities

Students have created their own websites which have created stimulated in the village and in local activities and production. Through the influence of international volunteers and visitors, the students have become exposed to a wide range of potential careers, especially those in the ICT sector.

In a study conducted by the Horizon Lanka Foundation it was found that an average of 4 job seekers come to the center every week to use the resources of the Foundation. ${ }^{11}$ This number

$9 \quad$ These additional costs were covered by ETPL

10 “Community Mesh Network for Mahavilachchiya, Sri Lanka”, November 1, 2006, Enterprise Technology (Pvt) Limited, ICTA, Horizon Lanka

11 In a study conducted by Nirosh and Chamila from Horizon Lanka in October 2005, Internet usage was monitored weekly for the month of October. While this study is useful in determining how many children and adults used the Internet during the first full month of implementation, it is not fully reliable. The data collected on Internet usage is highly subjective as it was self reported by the children themselves. The children are unlikely to report the actual reasons they were using the Internet if they deviated from the norm. A future study could use monitoring software or involve random checks in order to approximate actual Internet usage. 
is expected to increase as more villagers become ICT literate and aware of the Horizon Lanka facilities.

Potential use: Business Processing Outsourcing (BPO) or other outsourcing work could be done by trained students in Mahavilachchiya. Buying and selling goods could also occur over the Internet. For example, farmers could compare prices of farm equipment and local products and services could be sold online. National NGOs involved in activities such as craft production could be partnered with the e-village to increase business.

\section{Community chat}

Online chat is very popular among the students and they use chat to communicate with each other after school. The students also chat with past volunteers, their international sponsors, and friends and relatives in other parts of Sri Lanka.

Potential use: students could use chat to pass messages about relevant local events. A community website or chat room utilized by the students could help with dissemination of important local information

\section{Dissemination of health and educationally important information}

The students do not regularly view health related sites and the Internet has not yet replaced the need to go into the city for medical consultation. Students occasionally research medical conditions using Internet searches but this is rare.

Potential use: Students could research and write about health and safety issues for distribution in the village. A communications system could be set up with a hospital in case of a medical emergency.

Spreading information on how to face current environmental conditions

The students and their families all enjoy reading the Sinhala news online. This gives them access to current country conditions and any changes in the political situation.

Potential Use: Once a few more adults are ICT literate, they can access websites with current weather conditions and crop prices. They can also get information from sites such as the Department of Agriculture website which has information on how to prepare for environmental conditions and farming alternatives.

\section{Long-term Survival}

After the mesh network had been implemented, questions of project maintenance and replication arose. The e-village was created so that it could be scalable and replicated throughout Sri Lanka. The project should not collapse after its completion and reliance on external donors and stakeholders should be reduced. In the case of Mahavilachchiya, ICTA and other stakeholders have made an initial investment of time and money to create a mesh network. The project is currently not independently run although Horizon Lanka has been working on making it so.

Long-term survival for Mahavilachchiya involves both the maintenance of the organizational structure of the Horizon Lanka Foundation as well as financial stability so that the project is not reliant on the funds of a few individual donors. In the first case, the administration of the foundation must be strengthened and the responsibilities divided amongst a group of 
stakeholders such that if one person drops out, the project can continue. The stakeholders must participate in design and implementation and periodically be involved in evaluating the project.

For Mahavilachchiya to become financially sustainable, plans need to be in place to generate income. The fees to maintain the network are born by the supervisory agencies. The connectivity fees are met by ICTA and ETPL paid the salaries of the network monitors. Other fees for the maintenance of computers and facilities are paid by individual donors but they are often insufficient.

Before plans for e-commerce, BPOs, or other business can take place, some amount of longterm planning must come from the users and the Foundation. The creation of a solid business model and development of a support network through stakeholders will help in insuring a sustainable future for the e-village.

\section{Part 2: Uses of ICT in Mahavilachchiya}

At the time of writing, the mesh network had been up and running in Mahavilachchiya for a little over 3 months. The researcher traveled to Mahavilachchiya and lived at the home of one of the Horizon Lanka students for a period of 5 days. During this time she observed the casual Internet use which took place in student's homes as well as the formal training given by the Horizon Lanka Academy. The survey instrument was crafted after 3 days of observation of the students' English communication ability and Internet usage.

The purpose of the survey was to study Internet usage among Horizon Lanka students. The mesh network has been operational in Mahavilachchiya for 3 months and this survey aims to quantify the impact it has had on the lives of Horizon Lanka students. The survey methodology is attached as Appendix A and a copy of the survey is attached as Appendix B.

The following is a summary of relevant results and responses to particularly pertinent questions. A more detailed description of survey results can be found in Appendix C.

Of Mahavilachchiya's 22,000 people the Internet reaches roughly 1,000. According to the survey results, there is an average of 5 people per household for each Horizon student. Internet is currently in the homes of 28 students, therefore reaching roughly 140 people in their homes.

Through computers in homes and at the Horizon Center, there are many residents who have proximity to the Internet or to a frequent Internet user. Although many of the family members of Horizon students are not yet ICT literate, it is hoped that with time, the students will educate family members about the computer and relevant computer applications.

Of the 35 students surveyed, 24 have a computer at home with 20 students having Internet connectivity. There is a direct relationship between having the Internet at home and using it daily. This is represented in the graph below. There is no relationship between the hours of daily use and whether or not the student had a computer at home, probably because motivated students may go to the Horizon Center. 


\section{Student Internet Usage}

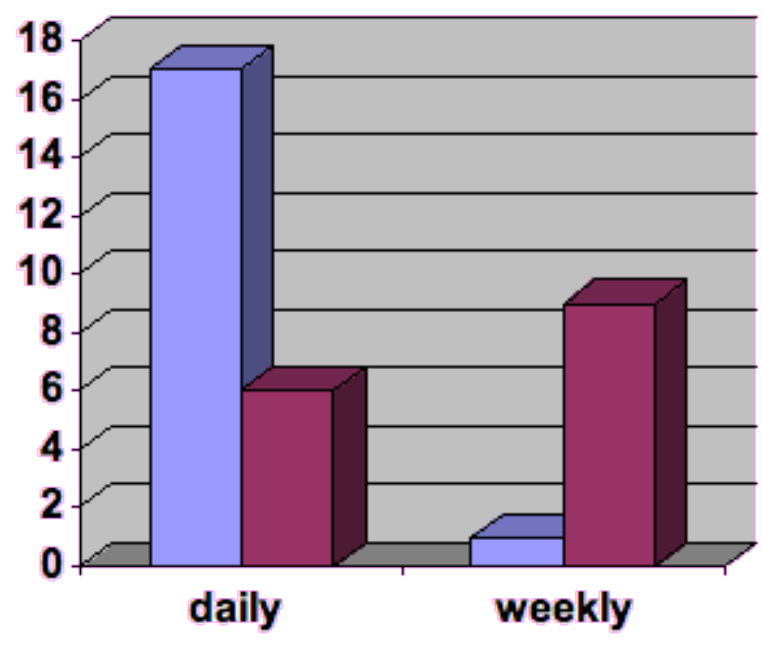

\begin{tabular}{|l|}
$\square$ Internet at home \\
$\square$ no Internet
\end{tabular}

The number of years of English study varied among the students, with an average of 6 years of English study per student. For most students, the years they had been studying English corresponded to the number of years they had been in Horizon. The older students, who were more comfortable with English, were able to give the researcher multiple responses to the survey question on Internet use. The younger students only gave one response. Despite the older student's familiarity with English, many of them desired more Sinhalese content. The various uses of the Internet by Horizon Lanka students are shown in the graph below.

\section{Internet Use}

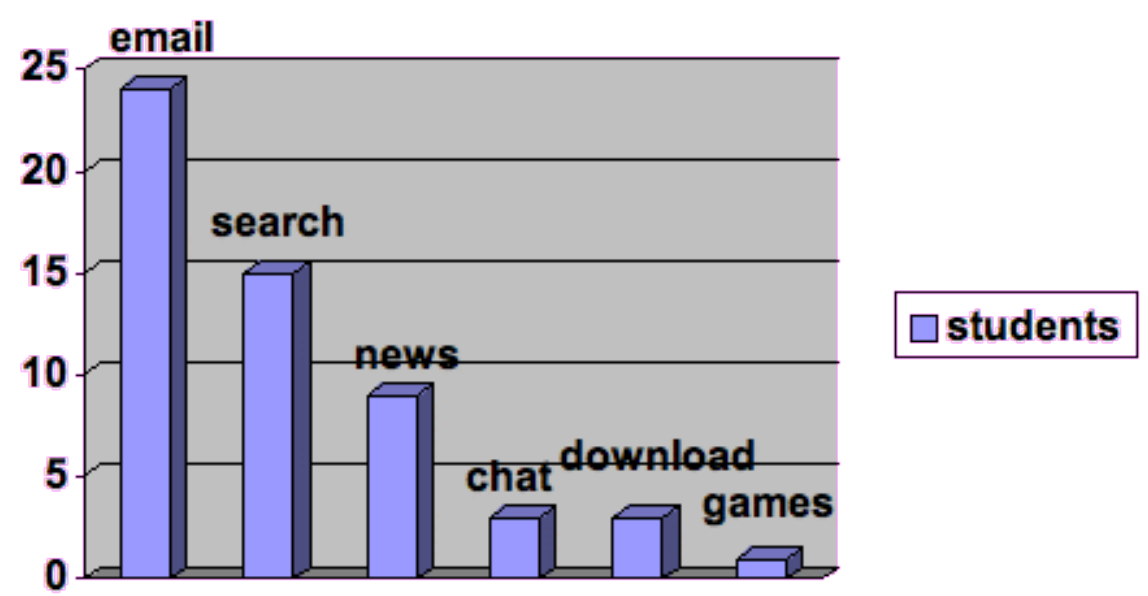

The majority of students use the Internet for schoolwork. They use Internet searches to conduct research. In fact, search engines are their favorite sites. This differs from their most recently viewed sites.

Looking at the most recently viewed site provides another indicator of popular uses for the Internet. Students may have certain favorite sites but looking at the most recently viewed site 
provides a glimpse into which sites were actually being used by the students. This information is shown in the graphs below.

\section{Favorite Internet Site}

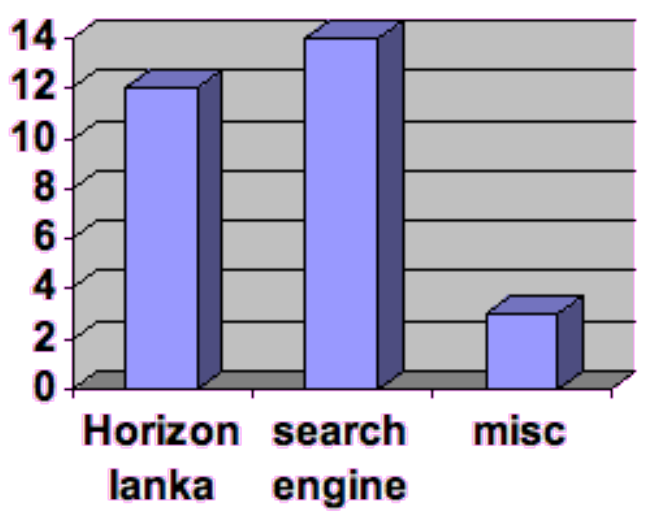

$\square$ students

\section{Most Recently Viewed Site}

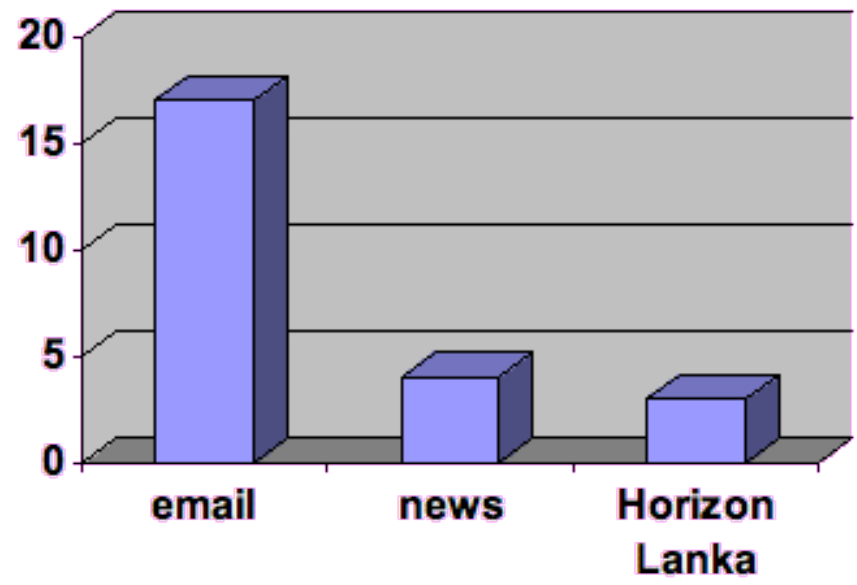

$\square$ students

Students have ambitious plans for the future, with many of them desiring computer-related jobs including programmer, web designer, and computer engineer. The remaining students desire jobs as teachers, doctors, and engineers. Seven students, mostly older students, also expressed a desire to work abroad. 


\section{Career Choice}

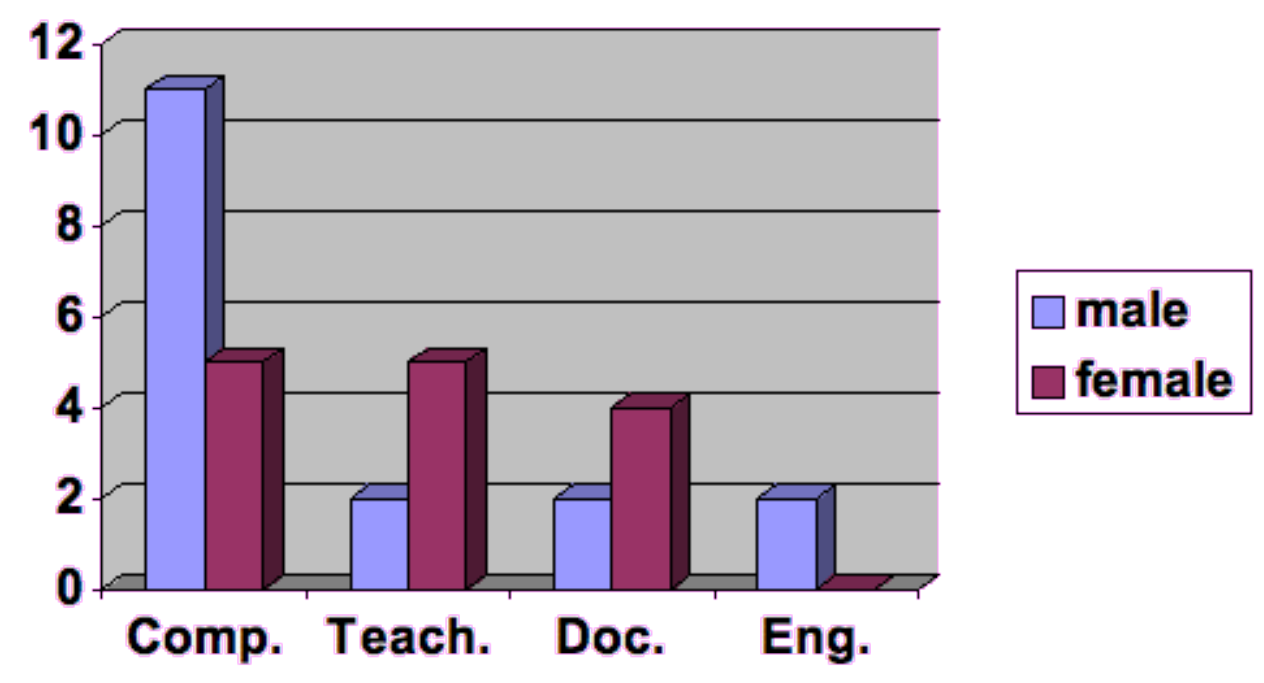

\section{Survey Conclusions}

Internet usage in the village is strongly linked to English education. ${ }^{12}$ Only those who have at least a basic grasp of English are able to navigate various Internet functions. ${ }^{13}$ The senior students, the ones who are the most fluent in English, are the students who are able to utilize a wide range of functions when they use the computer. These students were the most responsive to the survey and gave the researcher a great deal of feedback on survey questions. The students who are weaker in English use only a few functions such as chat and were less responsive to the survey.

The survey results demonstrate the effect of Internet penetration on the ways in which the students think about ICT. The responses show an increased exposure to international ideas and the world outside of Mahavilachchiya. The desire of many students to live and work abroad is one such example. Career choice also demonstrates a broadening of horizons. The most popular career choice among men and women is an ICT related career. Particularly interesting is the desire by so many female students to work in the ICT sector. In a village where there exist very few career opportunities for women, this demonstrates a concrete change in thinking.

Having Internet in the home greatly increased the amount of time students spent online. This is particularly beneficial as the majority of students use the Internet for assistance with schoolwork. Many students who utilize the center listed email, search engines, and chatting as some of their most preferred activities. Students are communicating with their friends and

12 Computer literacy and English literacy build upon each other. Although according to the study "Computer Literacy of Teachers" by Dr. Amara Satharasinghe, Deputy Dirctor, Department of Census and Statistics, Sri Lanka "A statistical test carried out on relationship between English language literacy, computer awareness, and computer literacy shows there is no significant relationship between English language literacy and computer awareness but there is a significant positive relationship between computer literacy and English language literacy." The students in Mahavilachchiya have been learning both. http://www.statistics.gov.lk/education/article.pdf

13

This limits the use of ICT by adult members of the community. While many of the adults enjoy reading local language newspapers online, they cannot operate computers by themselves and require a great deal of assistance from Horizon Lanka students. 
others through email and online chat. The frequency in which students listed email and search engines as their most popular uses for the Internet indicates the primary uses of the Internet and suggests that more education is necessary to teach students about other applications.

More Sinhalese content was desired by the older students although it is unclear as to what specific type of content they would like to see and what it would be used for. Many citizens, such as the adult residents of Mahavilachchiya, are limited in their uses of the Internet. Parents of the students are limited to browsing Sinhalese news sites. The desire for more Sinhalese content is indicative of the larger ICT for development problem of not having sufficient local content.

It is impossible with such a short survey to be able to determine the full breadth of applications for which the Horizon Lanka students use the Internet. Students, through exposure to promotional materials, are accustomed to giving certain responses in line with the goals of the Foundation. It is possible that students are viewing sites or using the Internet for functions such as downloading movies, which they under-reported in the survey. The students knew that the researcher was a representative from ICTA and this knowledge may have caused them to edit some of their responses.

Future work remains to be done once the Internet has saturated more of the Mahavilachchiya community and once the students have had longer exposure to it. A future survey should be more comprehensive and not totally reliant on student responses. The use of tracking software to determine the specific sites visited and time spent on each site might be useful in demonstrating how students really use the Internet.

\section{Part 3: Criticism and Recommendations}

There is a tendency in writing such reports to enumerate the many ways in which village life has changed for the better after the implementation of technology. It is important to note that ICT and specifically the Internet can have a negative impact on communities as well. Mahavilachchiya is not immune to the problems of unchecked Internet usage. In an article published in the Hindu: Business Line, October 23" 2006 entitled "Rural Surfers find more uses for IT than Agribusiness," $"$ Internet usage is monitored in rural India and the findings are quite surprising.

The general perception of Internet use in rural areas is that it is used primarily for educational information such as weather reports and agricultural information. A pilot survey on rural Internet usage in Maharashtra and Uttar Pradesh however, demonstrated how wrong this assumption can be. Using a software tool developed by Microsoft, 13 kiosks in the two States were tracked for 120 days.

The results were quite startling. In Maharashtra, agriculture sites only made up 2\% of the total usage. $23 \%$ of the time spent on the Internet was spent reading newspapers followed by $19 \%$ of the time sending email. Checking exam results made up another $15 \%$ and pornography made up $13 \%$ of total usage. The additional $28 \%$ of usage was spent on sports, job sites, music, search engines, and other miscellaneous sites.

These numbers are significant because they demonstrate the difference between predicted and actual usage. It is important to realize that people in rural areas are also susceptible to

14

Vyas, Priyanka, "Rural Surfers Find More Uses for IT Than Agribusiness" ( The Hindu Business Line, 23/10/06, India) http://www.thehindubusinessline.com/2006/10/23/stories/2006102302920100.htm 
negative content on the Internet such as pornography or extremist websites and that this media can have a negative impact on the local community.

The same statistics are probably not true for Mahavilachchiya as the Internet users in the village have a different age, gender, and cultural background than the rural farmers in Maharashtra monitored by the Microsoft software. However the statistics do reveal usage trends for Internet use in rural areas.

Firstly, the fact that only $2 \%$ of the time was spent on agricultural sites indicates that either farmers are not taking full advantage of Internet resources or that relevant resources do not exist. It is also important to consider that very few farmers are ICT literate, something that is certainly true in the Mahavilachchiya case.

Secondly, the time spent on email and newspapers reinforces the need for local language software to facilitate email communication and news. Roughly one quarter of all Internet usage was spent looking at news sites. This is reinforced by the results of the Mahavilachchiya student survey which revealed that nearly all of the adults who use the Internet use it for reading the newspaper in Sinhalese.

Finally, the large percentage of time spent on pornography (13\%) shows that rural people are not immune to negative aspects of Internet use and this must be addressed when ICTs are brought into a community. While the Internet brings in different ideas and knowledge, the influence of the Western porn industry on local communities is a significant threat. Internet porn can greatly affect the way that adolescents in Mahavilachchiya view themselves and their peers. There is the potential for detrimental Internet use if people are not properly educated on negative content before using the Internet.

The students were asked in the written survey if they had attended any programs on Internet awareness. They unanimously responded that they had not. It is important that awareness be raised among the students about appropriate and ethical Internet usage. Horizon Lanka is extremely understaffed and cannot monitor student usage. It is important that students are given this training so that they are aware of negative content.

\section{Criticism of the E-village}

Certain pre-existing village problems cannot be simply solved by ICT. The lack of job opportunities in the village, for example, can be partially remedied by fostering local industries but cannot be totally eliminated. Additionally the education system in the village has to be strong enough that students who use job-seeking sites are qualified to apply for jobs and can respond appropriately to job postings.

In an article criticizing the placement of ICT in a village that lacks basic infrastructure, Sailaja Neelakantan writes "Younger denizens of the village plan to use the Internet whenever they get a connection, no, make that if they ever get a connection - to help hasten their exit by searching online for college places and jobs in big cities. Not to be a total cynic, but most online content is in English, which they most likely don't understand well enough to access. And most of the jobs advertised online require qualifications beyond the purview of the village school system." 15

"What is a kid who goes to a school with rampant teacher absenteeism, no infrastructure to speak of -like desks, fans or electricity to run those fans -going to do with a laptop?"

15 Neelakantan, Shailaja, (GigaOM, 14/08/2006) http://gigaom.com/2006/08/14/indian-villages-Internetand-crazy-headlines/ 
These similar criticisms could be applied to Mahavilachchiya and are worth considering. The point made that English is required for students to be able to become fully ICT literate is one which Horizon is successfully tackling. By combining English and computer education, Horizon is ensuring that its students are well prepared to understand and utilize online content.

A lack of adequately trained teachers and insufficient modern equipment remain problems. The Horizon Lanka Academy is trying to provide a counterbalance to these problems by providing the students with modern technology, adequate sports and games equipment, and well-trained teachers. Horizon also recruits and hosts foreign volunteers in order to broaden the students' world-view and to improve their English skills.

The major question of whether or not the Horizon Lanka graduates really will be able to find better jobs and opportunities remains to be answered. The eldest batch is currently collegegoing so it remains to be seen if the Internet really does alleviate poverty in the region by allowing Horizon students to access a wider range of jobs.

Further criticism of the e-village could be made regarding the decision to implement the mesh network. No cost-benefit study was conducted on the part of ICTA comparing the mesh network to other methods of fostering ICT literacy such as busing students to Anuradhapura on weekends or giving select youth scholarships to study ICT. Perhaps prior research would have presented other options to the implementation of the mesh network. This research should be conducted before implementing future projects.

\section{Mahavilachchiya vs. the rest of Sri Lanka}

Mahavilachchiya stands at the forefront of ICT education in Sri Lanka. The Sri Lankan Department of Census and Statistics defines ICT literacy as "some sort of level of comfort around a computer other than a look or fear and foreboding." 16 The percentage of ICT literacy for the country in 2004 was only $10 \%$. The amount of Sri Lankans who were ICT literate in the North-Central provinces (where Mahavilachchiya is located) was only 5\% in 2004. The use of computers by the Horizon Lanka students and the presence of computers in homes have greatly increased the ICT literacy of Mahavilachchiya although the exact percentage is unknown.

The Mahavilachchiya e-village project has brought Internet connectivity to two schools in the region. One of these schools, Takshila Public School, has a computer lab and plans to get 20 computers by April, 2007. The other school, Saliya Mala Public School, has one computer with Internet connectivity. Each of these schools has 500-600 students. There are also plans to set up a computer center at a local police post. These ongoing projects are examples of ways in which the e-village of Mahavilachchiya is bridging the gap towards greater ICT literacy.

The Horizon Lanka Academy is one of the few schools in the country which has computers or Internet. According to the Department of Census and Statistics, in a study conducted in 2006 , only $17 \%$ of schools in Sri Lanka have a computer lab, $0.5 \%$ of schools have laptop computers, and only $6.4 \%$ of schools have an Internet connection. Horizon Lanka students have the great advantage of all three resources. The ability to use these resources, something which usually only students in cities have access to, helps in bridging the digital divide amongst rural and urban Sri Lanka as well as between Sri Lanka and the rest of the world.

16 Satharasinghe, Dr. Amara, "Computer Literacy of Sri Lanka”, (Department of Census and Statistics, 2004, Sri Lanka) http://www.statistics.gov.lk/cls2004/index.htm 


\section{The Future of Mahavilachchiya}

There is no long term plan for the future of Horizon Lanka and Mahavilachchiya. Without a concrete plan for the future, the outlook for Horizon Lanka seems uncertain. Rumors abound about staff members quitting, the involvement or disengagement of foreign donors, and the perception of Mahavilachchiya by various stakeholders. The researcher, in her short stay in Mahavilachchiya, was able to observe a few problem areas of the Mahavilachchiya e-village. Her observations are not by any means comprehensive of the full scope of problems.

The students have ambitious career goals but limited paths to seeing these goals materialize. Students desire ICT careers as programmers or graphic designers but are unclear as to how these goals can be achieved. Career guidance is desperately needed by the students as they lack basic job seeking skills such as making a resume and how to behave in an interview. Work remains to be done on employing the ICT literate students of Horizon Lanka.

Fundraising is another major problem at Horizon as it is an area that requires constant attention. There are many projects that have been begun through donor funds and were then abandoned, when the funding ceased. One such example is the gymnasium for which a foundation has been laid but the rest of the construction remains to be completed. Another manifestation of this is the irregularity of teachers' salaries.

There needs to be a constant, active, pursuit of economic sustainability options. Long-term fundraising mechanisms should be in place so that the project is not dependent on individual donors. Furthermore, income generation activities should be developed and pursued so that the project can be self-reliant and the local economy is developed. Various models for income generation exist. One option is to attract domestic corporate clients for a BPO. Another option is to try to get government contracts. Horizon Lanka must launch a diverse approach to sustainability including multiple strategies. ${ }^{17}$

Staffing is a large problem at Horizon Lanka due to an overall lack of funds. There are not enough teachers or administrative staff to run the Foundation smoothly. Furthermore the Foundation lacks a supervisory committee or strong administrative structure. The weight of business and administration functions cannot rest on Mr.Wanni, the founder, alone. The workload is too great for one person. Many of Mr.Wanni's duties should be handled by a professional staff supervised by an advisory board that would be involved in organizational and operational management. The board would ideally be composed of professionals in the ICT field. The members of the board, as a group, should have trustee and legal responsibility for the actions and operation of the organization. ${ }^{18}$

The volunteer program should also be revisited in order to alleviate some of the staffing problems. Recent political unrest has discouraged foreign volunteers from coming to Mahavilachchiya. A refocus needs to be made on attracting local and other volunteers. Volunteers with business and NGO administration expertise should be recruited along with teaching volunteers.

\section{Budget Sustainability Options}

Some costs of the e-village are covered by ICTA and other partners. ICTA pays for the cost of connectivity-approximately 29,000 SLR (250 USD) per month. Donations from third

$17 \quad$ Attracting domestic corporate clients and government clients is a strategy employed by GramIT, a successful Indian NGO in Andhra Pradesh. More information in the article by Steve Hamm, "Outsourcing Heads to the Outskirts", Business Week, January 22, 2007

$18 \quad$ More information on organizing an NGO can be found on the Global Development Research Center's site, http://www.gdrc.org/ngo/start-ngo/ 
parties are solicited by Horizon Lanka but come in sporadically. Horizon Lanka students are charged a monthly fee to be members of the Horizon Lanka academy. This fee is 250 SLR (\$.25 USD) per student. Horizon Lanka takes in roughly 37,500 SLR per month from students. This amount, according to the manager at Horizon Lanka, goes towards covering the costs of running the center. According to Mr.Wanni, the costs of running the center are 300,000 SLR (3,000 USD) per month. The center is completely reliant on donors to make up the deficit.

The e-village presents a unique challenge to financial sustainability. The Wi-Fi network in Mahavilachchiya enables anyone with a computer to use the Horizon Lanka network free of charge. Although anyone can use the network access becomes limited when people misuse it through using too much bandwidth. When users download large files such as movies, they hog bandwidth, limiting the extent to which other users can utilize the network.

Furthermore, only those with computers may use the network free of charge. Others must pay Horizon Lanka a small user fee. Numerous options for increasing revenue for Mahavilachchiya and future e-villages exist, each with their pros and cons. When Internet usage is not taxed, there is a tendency of users to take the network for granted and misuse it. When the network is taxed, this limits the number of potential users. A few of the options for income generation are as follows:

- The village as a whole could provide tax support as it is arguable that the entire village benefits from the Wi-Fi network and computer center.

- Internet users could be charged a fee for downloading beyond a certain amount. All users of the network would be allowed to use email and web browsing. However downloading beyond an established limit would incur a charge. In this way high bandwidth users would be limited and Horizon Lanka could make additional income heavy users. This could be implemented if the network expands to Anuradhapura, a neighboring town and thus expands its range of possible users.

- The government could finance e-villages through taxes, subsidies, or long-term loans made to local communities.

- The e-village could adopt an e-commerce model where goods and services from the village sold on the Internet and then transported to outside markets for example through BPO outsourcing or selling local products

- The e-village could link up with other NGOs that deal with rural economic development such as through cottage industries. The e-village could link these groups with outside markets and charge a fee for doing so.

- Remittances from e-village students who work outside of the village could be organized and made regular.

Certain options for increasing revenue, such as increasing user fees, are not feasible for the evillage project. The targeted audience of low-income villagers would be hurt by these increased fees and the number of people who would be able to use the Internet would be further limited. However, once the network expands beyond schools, corporate clients could be charged fees that would subsidize low-income users.

Recommendations for E-village:

Some things to consider when implementing other e-village networks:

1. Rural villages provide obstacles to ICT implementation including terrain and cultural sensitivity. The area which is to receive the mesh network should be studied before implementing the project and local people should be aware and receptive to ICT. A 
mesh network when there is line of sight between nodes can be extremely affordable. ${ }^{19}$ Barriers in physical implementation of the network should be taken into consideration.

2. ICT Training should target all segments of the population, especially underrepresented groups such as women. Training in local languages is particularly significant as it makes ICT more accessible. However it is important to realize that the majority of web content is targeted at English speakers. ICT education requires some familiarity with English. E-villages should only be started in villages where there is relatively high English proficiency and some computer literacy. In setting up an e-village, ICT and English training should come first, computers second, and connectivity should be the final step.

3. Simply setting up a network and expecting development and poverty alleviation to occur on its own is not realistic. In order for people to take full advantage of ICT for economic and educational opportunities, adequate training needs to take place. Villagers must be constantly educated and assisted in using ICT for development.

4. The role of a local champion, or team of champions, is crucial. This person(s) is responsible for serving as a liaison between development workers, government, and villagers. They should be well connected and respected within the village community in order to promote the e-village project.

5. For future e-villages a Foundation or NGO needs to be in place in the area to educate the villagers on ICT use and promote ICT education. A national organization which supervises smaller local-level teams would be very effective in disseminating the best practices and experiences across centers. Such a team would also make the whole project more sustainable.

6. There must be greater stakeholder participation in design and implementation of projects and the stakeholders should play an important role in monitoring and evaluating the project. One person should not bear too many of the responsibilities. The e-village administration should be designed such that executive power does not rest upon a single person and the project can continue beyond a few individuals.

\section{Conclusion}

ICT for development, like all development strategies, cannot occur in a vacuum. It is unreasonable to expect the mere presence of ICT to immediately uplift and develop an area. Internet connectivity, while connecting people with the outside world, is not effective if one does not know how to utilize ICT for economic and social development. Without such knowledge a rural ICT project cannot be sustainable. However it is also unreasonable for a development project to immediately become sustainable after its inception. The Mahavilachchiya mesh project has been up and running for roughly 5 months and cannot be expected to make large-scale developmental changes immediately.

In these five months, the impact of the Internet connectivity provided by the mesh network has been immense. Students who had no viable career paths outside of the village now plan to become programmers and graphic designers. There is greater communication with the outside world. The English skills of students in the village have been improving. Plans are also in place to attract a BPO to the village. The enthusiasm and creativity in which the people of Mahavilachchiya have been using ICT demonstrates that the Internet has truly been changing lives.

19 Another example of a community wireless mesh network exists in Tibet and is run by the TibTec NGO. www.tibtec.org. 
What Mahavilachchiya lacks is a clear vision for the future. More development work needs to take place to ensure that the work done in Mahavilachchiya is not in vain. The students of Mahavilachchiya need guidance in learning to utilize the Internet for socio-economic growth. Additional work though partnerships with other NGOs and the assistance of trained professionals could help the Mahavilachchiya e-village achieve its fullest potential.

With time the costs of implementing a mesh network will decrease further, making it even more accessible for use in creating future e-villages. When replicating the project a refocus must be made on development partnerships. The Mahavilachchiya case demonstrates that Internet alone will not immediately cause large-scale developmental change in a region. Internet connectivity must be provided as part of an integrated plan with other developmental partners so that the resource is fully utilized and positive change occurs.

\section{References}

Enterprise Technology (Pvt) Limited, Horizon Lanka (2006, November 1) Community Mesh Network for Mahavilachchiya, Sri Lanka

GramIT (2006) Byrraju Foundation http://www.byrrajufoundation.org/gramit.htm

Hamm, Steve (2007, January 22). Outsourcing Heads to the Outskirts. Businessweek

Immunization Financing (2007) World Health Organization http://www.who.int/immunization financing/analyses/fsp/process/en/index.html

Mathes, Rohan, (2007, January 8) President Stresses Integrated Village Development, Daily News http://www.dailynews.1k/2007/01/08/

Neelakantan, Shailaja, (2006, August 14) Indian Villages, Internet, and Crazy Headlines. GigaOM, http://gigaom.com/2006/08/14/indian-villages-Internet-and-crazyheadlines/

Satharasinghe, Dr. Amara, (2004) Computer Literacy of Sri Lanka. Department of Census and Statistics, http://www.statistics.gov.lk/cls2004/index.htm

Sathrasinghe, Amara (2006) Computer Literacy of Teachers, Department of Census and Statistics Report http://www.statistics.gov.lk/education/article.pdf

Srinivas, Hari (n.d.) Global Development Research Center, http://www.gdrc.org/ngo/start-ngo

Tibetan Technology Center, (2007) Tibetan Technology Center, www.tibtec.org

Vyas, Priyanka, (2006, October 23) Rural Surfers Find More Uses for IT Than Agribusiness. The Hindu Business Line http://www.thehindubusinessline.com/2006/10/23/stories/2006102302920100.htm

Mahavilachchiya e-village partners:

ICTA, (2005) ICT Agency of Sri Lanka www.icta.lk

Horizon Lanka, (2006) HorizonLanka Foundation www.horizonlanka.org

Enterprise Technology. (2006) Enterprise Technology (Pvt) Ltd. http://www.enterprisetl.com/

UNDP-APDIP, (2007) Asia-Pacific Development Programme, http://www.apdip.net/ 


\section{Appendixes}

\section{Appendix A}

Survey Methodology:

The survey was developed by the researcher (the author of this paper) and tested on 3 Horizon senior students. Some words in the initial version such as "exist" were too difficult for the students and were edited by the researcher for the final survey instrument. The survey was administered to 37 Horizon students on 6/1/07 during the morning classes. The survey was given to 20 boys and 15 girls. The students ranged in age from 12 to 18 . The senior students were given the survey first and then served as testing monitors for the subsequent two batches of students. The survey yielded 35 responses as the English skills of two of the students surveyed were not adequate for answering the questions.

The survey sample is representative of the students attending Horizon Lanka. According to the January 2007 roster, there are approximately 150 students currently enrolled at Horizon Lanka Academy. On the day the survey was administered roughly 55 students arrived for classes. The youngest 20 students were not included in the survey as their English skills were not adequate for reading and comprehending the questions. Roughly one third of the 110 ageappropriate students in Horizon Lanka were surveyed by this instrument.

The researcher instructed the students in English that they were supposed to answer the questions to the best of their ability and there were no right or wrong answers. The students were also prohibited from talking during the survey administration and were physically separated in order to diminish the risk of them copying responses from each other. When students had questions they raised their hands and the researcher or the testing monitors clarified the question or, when necessary, translated it to Sinhalese. The testing monitors were prohibited from giving the students examples of responses. Students were instructed to give no response if they could not think of an answer.

The average time it took to complete the survey varied with the senior students requiring 20 min, the next batch (14-16 years old) requiring $35 \mathrm{~min}$ and the final batch (12 to 14 years old) requiring $50 \mathrm{~min}$. The final batch of students found the survey quite difficult with many of them needing clarification on nearly every question. The survey is attached to this report as Appendix B.

\section{Appendix B}

Horizon Lanka Student Survey: January $6^{\text {th }}, 2007$

The purpose of this survey is to better understand the impact that the

Internet has had in Mahavilachchiya. Thank you for your cooperation.

What is your name? 


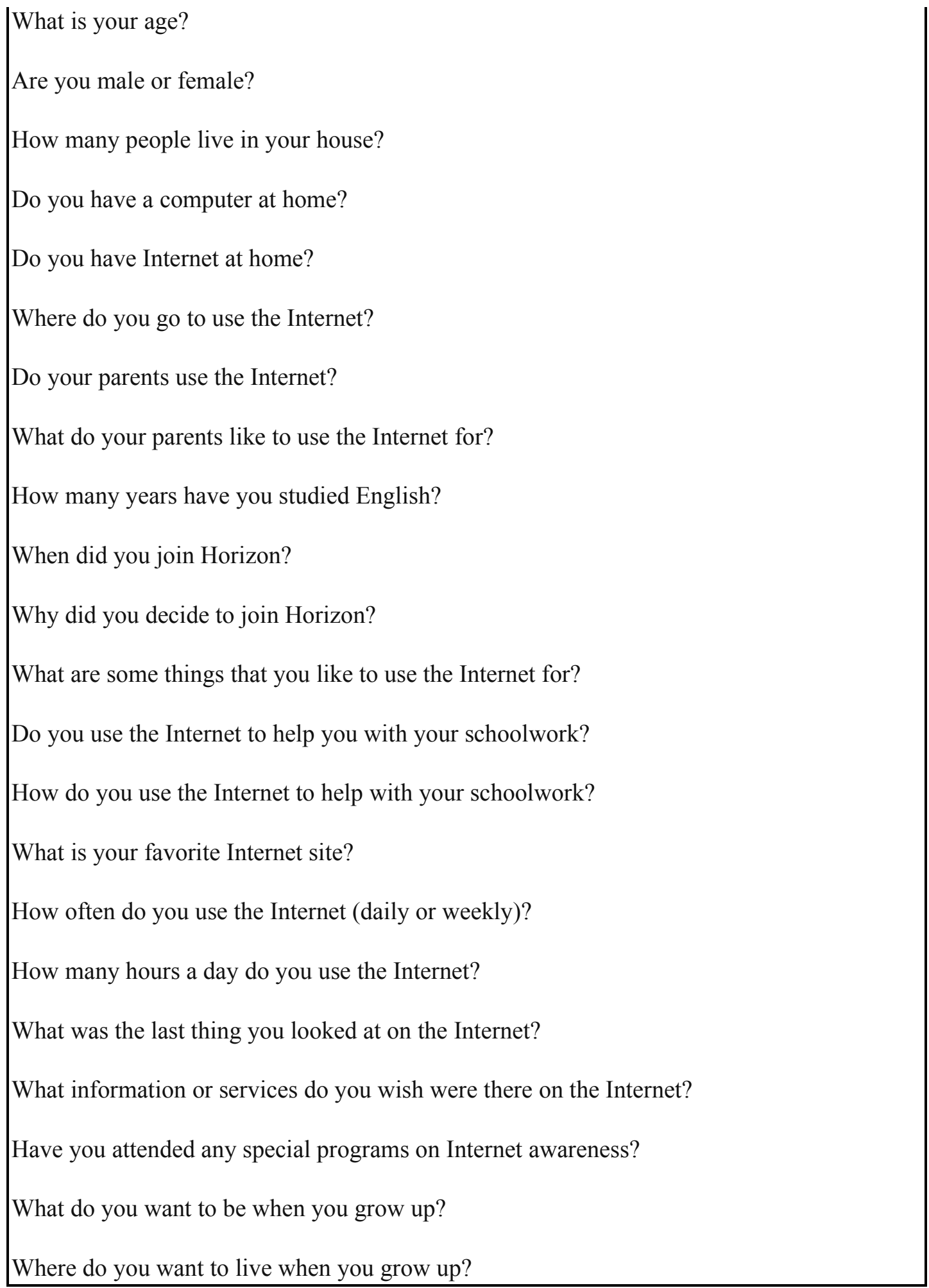

\section{Appendix C}

What is your name?

This question was asked in order to hold the students accountable for their answers. It is unclear if the students would have taken an anonymous survey with the same discipline and 
care that they completed the non-anonymous survey. The names of the students are not relevant for this study and have not been included in this report.

What is your age?

The ages of students ranged from 10 years to 19 years. The average age was 14.5 and the mode was 13.

Are you male or female?

The surveyed students were composed of a group of 20 males and 15 females. It is also worth noting that of the 7 senior students ages 17-19, gender was skewed between 6 females and 1 male

How many people live in your house?

The population of Mahavilachchiya is 22,000 people with Internet reaching roughly 1,000 people. According to the statistics compiled by the district secretariat, there are approximately 6,100 households in Mahavilachchiya. ${ }^{20}$ According to the survey results, there is an average of 5 people per household for each Horizon student. Internet is currently in the homes of 28 students, therefore reaching roughly 140 people in their homes.

If there are approximately 150 current students in Horizon, there are 150 households or roughly 750 people who have proximity to the Internet or a frequent Internet user. Although many of the family members of Horizon students are not yet ICT literate, it is hoped that with time, the students will educate family members about the computer and relevant computer applications.

Do you have a computer at home?

24 of the students surveyed have a computer at home. 11 students do not have a computer at home.

Do you have Internet at home?

20 of the students surveyed have Internet at home. 15 students do not.

Where do you go to use the Internet?

Data analysis was not carried out on this question as all students who responded gave "Horizon Lanka" as their response. Within Mahavilachchiya, Horizon Lanka is the only location available to the students to use the Internet aside from individual homes.

Do your parents use the Internet?

This question resulted in mixed answers. Some students defined Internet use as manipulating the computer and therefore did not consider their parents to be Internet users. Other students defined Internet use as looking at or listening to a computer and replied "yes" to this question. From an informal verbal poll of the students, none of the parents were ICT literate and were dependent on the children to show them content on the computer.

${ }^{20}$ District Secretariat, Mahavilachchiya, Anuradhapura, statistics compiled for 2006 
What do your parents like to use the Internet for?

Students overwhelmingly responded that their parents used the Internet for reading Sinhalese newspapers. Again, this did not mean that the parents manipulated the computer to pull up mews sites. Rather, the parents asked the children to find them news sites and then read newspapers off the computer screen once the child had called up the website.

How many years have you studied English?

Number of years of English study varied greatly with one student having only 2 years of study and one of the senior students having 12 years of study. The average number of years of English study is 6.

When did you join Horizon?

For 19 students the number of years in Horizon corresponded to the number of years of English study. 15 other students had been studying English for a year or two before joining. Only one student claimed to have been attending Horizon Lanka for a year before he began English study.

Why did you decide to join Horizon?

Data analysis on this question was not carried out because all students who responded gave English, computers, or both as their response. There are a few explanations for this, one being that the students are so accustomed to being asked about Horizon that "computers and English" is their stock answer. Another reason might be that these two aspects of learning are especially stressed in the Horizon academy and students think of them first when then think about Horizon Lanka.

What are some things that you like to use the Internet for?

Some of the older students gave multiple answers for this question. 24 students liked to use the Internet for email, 15 students gave research as their reply, and 9 students liked to look at the news. 3 students indicated chat as a favorite use, another 3 indicated downloading, and one student truthfully replied that he enjoyed playing games on the computer.

Do you use the Internet to help you with your schoolwork?

Students overwhelming responded in the positive to this question with only 4 out of the 35 students saying that they did not use the Internet for help with schoolwork. Of the four students who did not use the Internet for schoolwork, 2 have Internet at home and 2 do not.

How do you use the Internet to help with your schoolwork?

Data analysis on this question was not carried out as students unanimously answered that Internet searches/research was how they used the Internet to help them with their schoolwork.

What is your favorite Internet site?

12 students responded that the Horizon Lanka site was their favorite while another 12 responded that www.google.com was their favorite site. 2 students said that www.yahoo.com 
was their favorite and three individual students listed a news site, a cartoons site, and email as being their favorites.

How often do you use the Internet (daily or weekly)?

23 students use the computer daily and 10 use it weekly. There is a direct correlation between having the Internet at home and using it daily. Of the 20 students who have Internet at home, 17 use it daily and only one uses it weekly. Of the 15 students who do not have Internet at home 6 use it daily and 9 use it weekly.

How many hours a day do you use the Internet?

Students use the Internet for an average of 2 hours a day. There was no correlation between hours spent on the Internet and whether or not a student had Internet at home. This is due to the availability of computers at the Horizon Lanka facility. The facility is open to all students after school and many students walk in to use the computers during the afternoons and evenings.

What was the last thing you looked at on the Internet?

17 students responded that the last site viewed was an email site, 3 stated they had been looking at the Horizon Lanka webpage, and 4 said they had been reading the news.

What information or services do you wish were there on the Internet?

This question was very difficult for students to answer and some of them spent 10-15 min thinking about this question alone. Even the senior students had difficulty answering this question. Only 10 students answered the question at all with 5 of them listing an answer related to wanting more Sinhalese content. Out of the other 5 respondents, two listed "information", one listed "educational content", one listed "more information for rural villagers" and one listed "TV shows".

Have you attended any special programs on Internet awareness?

This was to determine if the students have had any formalized instruction or workshops on ethical computer usage. The students unanimously answered no and when probed further revealed that no such lesson had been given to them either formally or informally. The teachers admitted to discouraging the students from playing games on the Internet but not actively censoring or commenting on what content students view.

What do you want to be when you grow up?

Computer-related jobs including programmer, web designer, and computer engineer were the most popular choices with 18 students selecting a computer related job. 7 students selected teacher, 6 selected doctor, and 2 indicated they would like to be engineers.

Where do you want to live when you grow up?

The majority of students, 28, gave Sri Lanka as their response, some respondents specifying Mahavilachchiya. The other 7 students listed various foreign countries. 